\title{
Correlation of cytokine level with the severity of severe fever with thrombocytopenia syndrome
}

\author{
Miao-Miao Liu', Xiao-Ying Lei ${ }^{1}$, Hao Yu' ${ }^{2}$, Jian-zhi Zhang ${ }^{3}$ and Xue-jie $\mathrm{Yu}^{1,4^{*}}$
}

\begin{abstract}
Background: Severe fever with thrombocytopenia syndrome (SFTS) was an emerging hemorrhagic fever that was caused by a tick-borne bunyavirus, SFTSV. Although SFTSV nonstructural protein can inhibit type I interferon (IFN-I) production Ex Vivo and IFN-I played key role in resistance SFTSV infection in animal model, the role of IFN-I in patients is not investigated.

Methods: We have assayed the concentration of IFN-a, a subtype of IFN-I as well as other cytokines in the sera of SFTS patients and the healthy population with CBA (Cytometric bead array) assay.

Results: The results showed that IFN-a, tumor necrosis factor (TNF-a), granulocyte colony-stimulating factor (G-CSF), interferon- $\gamma$ (IFN- $\gamma$ ), macrophage inflammatory protein (MIP-1a), interleukin-6 (IL-6), IL-10, interferon-inducible protein $(\mathrm{PP}-10)$, monocyte chemoattractant protein (MCP-1) were significantly higher in SFTS patients than in healthy persons $(p<0.05)$; the concentrations of IFN- $a$, IFN- $\gamma$, G-CSF, MIP-1a, IL-6, and IP-10 were significant higher in severe SFTS patients than in mild SFTS patients $(p<0.05)$.

Conclusion: The concentration of IFN- $a$ as well as other cytokines (IFN- $\gamma$, G-CSF, MIP-1a, IL-6, and IP-10) is correlated with the severity of SFTS, suggesting that type I interferon may not be significant in resistance SFTSV infection in humans and it may play an import role in cytokine storm.
\end{abstract}

Keywords: Severe fever with thrombocytopenia syndrome (SFTS), Cytokine storm

\section{Background}

Severe fever with thrombocytopenia syndrome (SFTS) is an emerging hemorrhagic fever in East Asia that is caused by a tick-borne bunyavirus, SFTSV [1]. The major clinical manifestations of SFTS included acute fever $\left(\geq 38{ }^{\circ} \mathrm{C}\right)$, thrombocytopenia, leucopenia, gastrointestinal symptoms, central nervous system (CNS) symptoms, and multiple organ dysfunctions [1-3]. The case fatality rate of the disease ranged from 12 to $30 \%$ in China and is even higher in Japan [1, 4]. However, the pathogenic mechanism of the disease was not well studied. Previous studies suggested that a cytokine storm might be associated with the development of the disease [5-7].

\footnotetext{
* Correspondence: xuyu@utmb.edu

${ }^{1}$ School of Public Health, Shandong University, Jinan 250012, China

${ }^{4}$ Department of Pathology, University of Texas Medical Branch, Galveston,

Texas 77555-0609, USA

Full list of author information is available at the end of the article
}

Cytokines are a group of small proteins which are essential for fighting off infections. However, overproduction of cytokines could trigger a dangerous situation known as a cytokine storm. The nonstructural protein of SFTSV has been described to inhibit type I interferon (IFN-I) production in cell culture [8,9]. Mouse is naturally resistant to SFTSV infection, but IFN- $\alpha$ receptor (IFNAR) deficient mouse is highly susceptible to SFTSV infection [10]. These studies suggested that IFN-I may play an important role in resistance SFTSV infection. However, the role of IFN-I in resistance SFTSV infections has not yet been investigated in humans although the role of other cytokines has been well studied by several reports. The aim of this study is to determine the concentration of IFN- $\alpha$, a subtype of IFN-I as well as the concentration of other cytokines in SFTS patients and in the healthy population. By analyzing the differences in cytokine concentrations between severe SFTS patents 
and mild SFTS patients and between SFTS patients and the healthy population, we attempted to determine the role of IFN- $\alpha$ and other cytokines in the pathogenesis of SFTS.

\section{Methods}

\section{Patient sera and clinical information}

The SFTS patients included in this study had met one or more of the following criteria: (1) SFTSV was isolated from the patient's serum, (2) SFTSV RNA was detected from the patient's serum by a quantitative reversetranscriptase polymerase chain reaction (RT-PCR) and (3) seroconversion or a 4-fold increase of antibody titers was detected between the acute and convalescent sera of the same patient. The sera of SFTS patients used in this study were obtained during the acute phase of the disease (within 2 weeks since onset). The sera of healthy persons were obtained from the persons who came to the hospital for physical examination. In accordance with the illness severity, the patients were divided into severe and mild groups $[2,3,6]$. Severe SFTS cases were defined as patient who required admission to an intensive care unit and met at least one of the following criteria: (1) acute lung injury (ALI) /acute respiratory distress syndrome (ARDS), (2) heart failure, (3) acute renal failure, (4) encephalitis, (5) shock, (6) septicemia, (7) disseminated intravascular coagulation (DIC), or (8) death.

\section{Multiplex cytokine assay}

The concentrations of serum cytokines were tested with $\mathrm{BD}^{\mathrm{max}}$ human soluble protein master buffer kits and $\mathrm{BD}^{\mathrm{mm}}$ CBA flex sets according to the manufacturer's instructions (BD Bioscience-PharMingen, San Diego, CA). The cytokines assayed in this study included tumor necrosis factor (TNF- $\alpha$ ), granulocyte colony-stimulating factor (G-CSF), interferon- $\gamma$ (IFN- $\gamma$ ), IFN- $\alpha$, macrophage inflammatory protein (MIP-1 $\alpha$ ), interleukin-6 (IL-6), IL-10, interferon-inducible protein (IP-10), monocyte chemoattractant protein (MCP-1), and regulated upon activation normal $\mathrm{T}$ cell expressed and secreted factor (RANTES).

\section{Statistical analysis}

The statistical analysis was performed using SPSS software 18.0 for Windows. Means for continuous variables were compared using independent-group Student's $t$ tests when the data were normally distributed; otherwise, the Wilcoxon rank sum test was used. The categorical variables were compared with $\chi^{2}$ test. A $p$-value $<0.05$ was considered statistically significant.

\section{Results}

Patient information

Fifty SFTS patients who were confirmed to be infected by SFTSV previously were enrolled in this study [11].
The mean age was $61.2(\mathrm{SD}=10.9)$ years old, and 17 (34.0\%) of them were male. In addition to the patients, thirty-eight age and sex matched healthy individuals were also enrolled. The mean age of healthy individuals was $62.7(\mathrm{SD}=13.2)$ years old, and 14 $(36.8 \%)$ of them were male. There were no significant differences between patients and normal subjects on the distribution of age and gender (Table 1). Among the fifty patients, thirty-six of them were mild patients and fourteen were severe patients. There was no difference on gender distribution between the severe patients (male, 28.6\%) and the mild patients (male, 36.1\%). However, the severe patients were significantly older than the mild patients (67.0 VS 59.5, $p=0.003$ ) (Table 2).

\section{Cytokine concentrations \\ Comparison of cytokine concentrations between SFTS patients and healthy population}

Except for RANTES, the concentrations of all tested cytokines including TNF- $\alpha$, G-CSF, IFN- $\gamma$, IFN- $\alpha$, MIP-1 $\alpha$, IL-6, IL-10, IP-10, and MCP-1 were significantly higher in SFTS patients than those in healthy individuals $(p<0.05)$ (Table 1$)$. The concentration of IFN- $\gamma$, IFN- $\alpha$, TNF- $\alpha$, G-CSF, MCP- 1 , and IL- 6 were moderately increased in SFTS patients than in the healthy population with 1 to 7 fold increases, whereas, the concentration of MIP-1 $\alpha$, IP-10, and IL-10 were extremely increased in SFTS patients than that in healthy individuals with 42 to 1228 fold increases. RANTES was the only cytokine that was decreased in SFTS patients than in healthy persons (4676.3 VS7220.0, $p=0.003)$.

Table 1 Comparison of age, gender and cytokine concentrations between SFTS patients and healthy population ${ }^{a}$

\begin{tabular}{llll}
\hline Characteristic & Patients $(n=50)$ & Healthy Individuals $(n=38)$ & $p$ Value \\
\hline Sex, male, $n(\%)$ & $17(34.0)$ & $14(36.8)$ & 0.782 \\
$\begin{array}{l}\text { Age, year, } \\
\text { mean (SD) }\end{array}$ & $61.2(10.9)$ & $62.7(13.2)$ & 0.554 \\
TNF-a & $1.2(0.6-1.6)$ & $0.0(0.0-0.3)$ & 0.001 \\
G-CSF & $7.6(5.5-18.7)$ & $4.0(3.5-4.4)$ & 0.027 \\
IFN- $\gamma$ & $10.8(4.6-34.5)$ & $2.2(1.7-2.6)$ & 0.001 \\
IFN-a & $14.1(6.5-29.5)$ & $2.4(1.9-2.8)$ & 0.001 \\
MIP-1a & $16.4(5.0-46.7)$ & $0.1(0.0-2.0)$ & 0.045 \\
IL-6 & $28.1(10.7-70.5)$ & $4.0(3.3-6.6)$ & 0.001 \\
MCP-1 & $156.7(88.9-407.9)$ & $37.7(20.7-61.3)$ & 0.005 \\
IL-10 & $1228.4(88.8-3960.9)$ & $1.0(0.8-1.7)$ & 0.002 \\
IP-10 & $2718.7(1389.9-5278.9)$ & $65.1(37.6-168.5)$ & 0.001 \\
RANTES & $4676.3(2982.4-7555.5)$ & $7220.0(5468.7-100115.6)$ & 0.003 \\
\hline
\end{tabular}

Unit: $\mathrm{pg} / \mathrm{ml}$; ${ }^{\text {aValues }}$ are listed as median range unless otherwise noted; SD, standard deviation 
Table 2 Comparison of age, gender and cytokine concentrations between severe and mild SFTS patients ${ }^{\mathrm{a}}$

\begin{tabular}{|c|c|c|c|}
\hline Characteristic & Mild patients $(n=36)$ & Severe patients $(n=14)$ & $p$ Value \\
\hline Sex, male, n (\%) & $13(36.1)$ & $4(28.6)$ & 0.613 \\
\hline Age, year & $59.5(49.3-65.0)$ & $67(62.0-73.5)$ & 0.003 \\
\hline TNF-a & $1.2(0.7-1.6)$ & $1.3(0.5-4.0)$ & 0.314 \\
\hline G-CSF & $6.9(5.3-10.6)$ & $20.1(11.7-49.1)$ & 0.001 \\
\hline IFN- $\gamma$ & $8.8(3.9-25.1)$ & $54.3(6.2-90.4)$ & 0.005 \\
\hline IFN-a & $11.0(5.3-18.8)$ & $26.9(14.3-138.3)$ & 0.001 \\
\hline MIP-1a & $12.1(2.5-30.7)$ & $56.4(20.6-222.0)$ & 0.001 \\
\hline IL-6 & $18.3(7.9-45.8)$ & $121.2(47.5-272.4)$ & 0.001 \\
\hline MCP-1 & $141.7(85.4-339.9)$ & $227.8(118.6-1185.4)$ & 0.115 \\
\hline IL-10 & 1188.7 (87.7-2436.2) & $3917.0(106.9-11025.9)$ & 0.210 \\
\hline IP-10 & 2178.0 (1260.8-3715.6) & $5385.2(3362.3-8394.3)$ & 0.003 \\
\hline RANTES & $4855.4(3070.1-7739.9)$ & 4195.5 (2728.6-6199.0) & 0.612 \\
\hline
\end{tabular}

Unit: $\mathrm{pg} / \mathrm{ml}$; ${ }^{\text {a }}$ alues are listed as median range unless otherwise noted

\section{Comparison of cytokine concentrations between severe and} mild SFTS patients

The results showed that severe SFTS patients were significantly older than the mild patients. In order to confirm whether age is an influencing factor for the concentrations of cytokines, the healthy individuals were divided into two parts according to their ages. There was no significant difference between the two parts on the concentration of cytokines (fifty percent of them were older than 65 years, data not shown). The concentrations of G-CSF, IFN- $\alpha$, IFN- $\gamma$, MIP- $1 \alpha$, IL-6, and IP-10 were significantly increased in severe SFTS patients than in mild patients $(p<0.05)$; whereas the concentrations of TNF- $\alpha$, MCP-1, IL-10 and RANTES did not significantly differ between the two groups of patients (Table 2). Severe SFTS patients exhibited a moderate 1.6 to 6.7 -fold increase in cytokine concentrations when compared to mild SFTS patients.

\section{Discussion}

Cytokines, a class of small molecule proteins with a broad range of biological activities, are mainly synthesized and secreted by immune cells [12]. According to their functions, cytokines can be divided into the following categories: chemokine, interferon, interleukin, colony stimulating factor, tumor necrosis factor, transforming growth factor and growth factor. They act through receptors and play an important role in host immune response to infections and cancer. Viral infections can stimulate the body to produce immune responses, including the innate immune response and adaptive immune response. TNF- $\alpha$ and IFNs are involved in the innate immune response, which is the first line of defense against viral infections. In the subsequent adaptive immune response, IL, CSF, chemokine and other cytokines play an important role [13].

The concentrations of most cytokines have been reported previously [5-7]. Our results were consistent with previous studies, indicating that the cytokine level of G-GSF, IFN- $\gamma$, IL-6, IL-10, TNF- $\alpha$, MIP- $1 \alpha$, MCP-1, and IP-10 were significantly higher in SFTS patients than in the healthy controls. Moreover, the levels of GCSF, IFN- $\gamma$, MIP-1 $\alpha$, IL- 6 , and IP-10 were significantly higher in severe SFTS patients than the mild patients.

Interferons are glycoprotein secreted by mononuclear leukocytes and lymphocytes in response to pathogens, such as viruses and bacteria, or tumor cells [14]. Based on the type of receptor, human interferons have been classified into three major types: interferon type I, interferon type II and interferon type III. In a typical scenario, a virus-infected cell will release interferons causing nearby cells to heighten their anti-virus defenses. IFN- $\alpha$ proteins produced by leukocytes [15] is a member of the type I interferon family, a multi-gene cytokine family that includes IFN- $\alpha$, IFN $-\beta$, IFN- $\varepsilon$, IFN- $\tau$, IFN- $\kappa$, IFN- $\omega$, IFN- $\delta$ and IFN- $\zeta$ in humans [16]. All IFN-I bind to a cell surface receptor complex, IFN- $\alpha$ receptor (IFNAR), consisting of IFNAR1 and IFNAR2 chains $[17,18]$. IFN-I has been found in all mammals and similar molecules have been found in fish, reptile and birds [17, 18]. IFN-I has diverse effects on innate and adaptive immune cells during infections, directly and/or indirectly through the induction of other mediators [19]. Normal mice are resistant to SFTSV infection, but IFNAR deficient mice became highly susceptible to SFTSV infection, suggesting the importance of IFN-I in resistance to SFTSV infection [10]. However, IFN-I has been shown to cause immunopathology in some acute viral infections, such as influenza virus infection [19]. The changes of IFN-I content during different viral infections varied. The level of IFN- $\alpha$ was significantly elevated in the serum of SARS and Hantavirus pulmonary syndrome patients $[20,21]$. However, another study indicated that the IFN-I response was not notable during hantavirus infection [22]. Given the importance of IFN-I against viral infections or in immunopathology of viral infections, it is surprising that only one article reported the IFN- $\alpha 2$ concentration in the serum of SFTS patients [2]. Our original hypothesis was that IFN-I should be low in severe SFTS patients than in mild SFTS patients because it had the function in defending against viral infection. However, our results showed the opposite, suggesting that high concentrations of IFN- $\alpha$ in SFTS patient could not control SFTSV, which may actually involve in cytokine storm. It is interesting to note that in vitro studies indicated that the non-structural proteins of SFTSV inhibits the generation of type I interferon to promote viral replication $[8,9,23]$. However, our results indicated that 
the level of IFN- $\alpha$ is significantly higher in SFTS patients than healthy persons. Moreover, IFN- $\alpha$ is also significant higher in severe SFTS patients than in mild SFTS patients. A previous study also indicated that severe SFTS patients had higher SFTSV viral loads in serum than mild SFTS patients [24]. Combining the results of our study and the previous study, we concluded that higher SFTSV viral load stimulate stronger IFN- $\alpha$ production in vivo, suggesting that non-structural proteins of SFTSV may be not important for inhibition of the production of type I INFs in vivo. Our result was different on IFN- $\alpha$ compared to a previous study, which showed no significant difference between severe and mild patients (2). The concentration discrepancy may be caused by different collection stage or storage condition.

Our results showed that IFN- $\gamma$ was also correlated to the severity of SFTSV infection, which is consistent with a previous study [2]. However, another study indicated that levels of IFN- $\gamma$ in non-severe cases were lower than values detected in healthy individuals [6].

G-CSF stimulates bone marrow to generate granulocytes and release them into the blood stream. It can stimulate the survival, proliferation, differentiation, and function of neutrophil precursors and mature neutrophils, which have phagocytosis and chemotaxis function against infection [25]. However, when the body was infected with SFTSV, the white blood cell count would progressively decrease [26-28]. G-CSF may be produced to increase white blood cells against SFTSV infection. Our study indicated that G-CSF is significantly increased in SFTS patients and it is correlated to the severity of SFTSV infection.

Interleukins are mainly expressed by leukocytes and their main functions are to promote the development and differentiation of $\mathrm{T}$ and $\mathrm{B}$ lymphocytes, and hematopoietic cells [29]. IL-6 plays an important role in inducing B cells to differentiate into plasma cells to produce antibody [30]. IL-10 down-regulates the immune response after virus infection by inhibiting IFN- $\gamma$ production, antigen presentation, and macrophage production of IL- 1, IL- 6 , and TNF- $\alpha$. IL-10 induces activated B cells to secrete large amounts of IgG, IgA, and IgM. Thus, IL-10 may play an important role in the amplification of humoral responses [31]. IL-6 and IL-10 are usually increased in viral infections. IL-6 and IL-10 were significantly elevated in Chikungunya fever patients compared to uninfected persons [32]. IL-10 level was significantly elevated at the early stage of Ebola infection [33]. The role of IL-10 in inhibiting antigen-stimulated $\mathrm{T}$ cell proliferation supports the assumption that a $\mathrm{T}$ cell-mediated response is critical for survival of Ebola virus infected patients [33, 34]. Both IL- 6 and IL-10 are significantly increased in SFTS patients and lL-6, but not IL-10 is correlated to the severity of SFTSV infection.
TNF- $\alpha$ is a monocyte-derived cytotoxin that can directly kill tumor cells and has no obvious toxicity to normal cells. By binding to the corresponding receptor, it participates in host antiviral response [35]. Consistent with previous studies, we demonstrate that the concentration of TNF- $\alpha$ is extremely low in healthy individuals (median $=0$, range: $0-0.3 \mathrm{pg} / \mathrm{ml}$ ); however, even in severe patients, its concentration is only $1.3 \mathrm{pg} / \mathrm{ml}$ (range: 0.5 4.0). There was no significant difference between the severe SFTS patients and the mild SFTS patients which suggested that TNF- $\alpha$ may not play an important role in the progress of infection as previously expected.

MIP-1 $\alpha$, MCP-1, and IP-10 are chemokines, a family of small signaling proteins mainly secreted by white blood cells. The major role of chemokine is to act as a chemoattractant to guide the migration of cells [36]. During the processes of immune surveillance, chemokine can regulate cells of the immune system, such as directing lymphocytes to the lymph nodes so they can screen for invasion of pathogens by interacting with antigen-presenting cells residing in these tissues [37]. Our study showed that the increase of both MIP-1 and IP-10 are significantly correlated to the severity of SFTSV infection. Several previous studies have also reported increase of these cytokines in SFTS patients $[2,6]$.

RANTES, a known chemoattractant for monocyte and $\mathrm{T}$ cells, is produced by many cell types, including endothelial cells and macrophages [38]. RANTES have an essential role in activation and proliferation of antigen-specific $\mathrm{T}$ cells [39]. It was the only indicator we studied that had a higher level in healthy subjects. Furthermore, its concentration was decreased in severe patients compared to the mild patients. This result was completely opposite with other cytokines. In a previous study, the level of RANTES decreased in SFTS patient which was consistent with our result [5]. However, in another study the concentration of RANTES in patients' sera was obviously increased compared to healthy persons [6]. The concentration discrepancy of RANTES in different studies may be caused by collecting the samples in different stage of infection.

Cytokine storm is a potentially fatal immune reaction consisting of a positive feedback loop between cytokine and white blood cells, with highly elevated levels of various cytokines [40]. Studies found that a variety of pathogen infections can cause a cytokine storm, which may cause acute respiratory distress syndrome and multiple organ failure [5, 41-43]. Previous studies demonstrated that SFTSV infection induced a cytokine storm with abnormally expressed cytokine profiles, which might be associated with the disease severity $[5,6,44]$. Consistent with our study, the elevated cytokines in those above studies included IP-10, G-CSF, IL-6, IL-10, MCP-1, and MIP- $1 \alpha$. However, the differences of TNF- $\alpha$ and IFN- $\gamma$ concentration between severe and mild SFTS patients 
were varied in different studies. Deng, et al showed that the concentrations of TNF- $\alpha$ and IFN- $\gamma$ were significantly higher in severe cases than non-severe cases [6]. However, there were people who also indicated that the production of TNF- $\alpha$ and IFN- $\gamma$ during the acute phase were only slightly elevated in severe cases [5]. In this study, most of the cytokines including G-CSF, IFN- $\gamma$, IFN- $\alpha$, MIP- $1 \alpha$, IL- 6 , and IP-10 were correlated to the severity of SFTSV infection.

\section{Conclusion}

Our results indicated that IFN- $\alpha$ as well as other cytokines including G-CSF, IFN- $\gamma$, MIP- $1 \alpha$, IL-6, and IP-10 were correlated to the severity of SFTSV infection, suggesting that type I interferon may not play a significant role in resistance SFTSV infection in humans and it may play an import role in cytokine storm involved in the pathogenesis of SFTS.

\section{Abbreviations \\ G-CSF: granulocyte colony-stimulating factor; IP-10: interferon-inducible protein; MCP-1: monocyte chemoattractant protein; MIP-1a: macrophage inflammatory protein; RANTES: Regulated upon activation normal T cell expressed and secreted factor; RT-PCR: Quantitative reverse-transcriptase polymerase chain reaction; SFTS: Severe fever with thrombocytopenia syndrome}

\section{Acknowledgements}

\section{Funding}

This study was supported by the National Natural Science Funds of China (31570167, 81401368), Shandong Province Science and Technology Development Program (2014GSF121004), Natural Science Foundation of Shandong Province, China(ZR2014HP025).

\section{Availability of data and materials}

The datasets during and/or analyzed during the current study available from the corresponding author on reasonable request.

\section{Authors' contributions}

MML performed the multiplex cytokine assay, and was a major contributor in writing the manuscript. All authors read and approved the final manuscript.

\section{Competing interests}

The authors declare that they have no competing interests.

\section{Consent for publication}

Not applicable.

\section{Ethics approval and consent to participate}

The experimental research reported in this study was performed with the approval of the ethics committee of Shandong University. Human research was carried out in compliance with the Declaration of Helsinki. All subjects have provided the written informed consent.

\section{Author details}

${ }^{1}$ School of Public Health, Shandong University, Jinan 250012, China. ${ }^{2}$ School of Medicine, Fudan University, Shanghai 200032, China. ${ }^{3}$ School of Health Professions, University of Texas Medical Branch, Galveston, Texas 77555-0609, USA. ${ }^{4}$ Department of Pathology, University of Texas Medical Branch, Galveston, Texas 77555-0609, USA.

Received: 29 September 2016 Accepted: 27 December 2016 Published online: 13 January 2017

\section{References}

1. Yu XJ, Liang MF, Zhang SY, Liu Y, Li JD, Sun YL, Zhang L, Zhang QF, Popov VL, $\mathrm{Li}$ C, et al. Fever with thrombocytopenia associated with a novel bunyavirus in China. N Engl J Med. 2011;364(16):1523-32.

2. Ding YP, Liang MF, Ye JB, Liu QH, Xiong CH, Long B, Lin WB, Cui N, Zou ZQ, Song $Y L$, et al. Prognostic value of clinical and immunological markers in acute phase of SFTS virus infection. Clin Microbiol Infect. 2014;20(11):0870-8.

3. Deng B, Zhou B, Zhang S, Zhu Y, Han L, Geng Y, Jin Z, Liu H, Wang D, Zhao Y, et al. Clinical features and factors associated with severity and fatality among patients with severe fever with thrombocytopenia syndrome Bunyavirus infection in Northeast China. PLoS One. 2013;8(11):e80802.

4. Takahashi T, Maeda K, Suzuki T, Ishido A, Shigeoka T, Tominaga T, Kamei T, Honda M, Ninomiya D, Sakai T, et al. The first identification and retrospective study of Severe Fever with Thrombocytopenia Syndrome in Japan. J Infect Dis. 2014;209(6):816-27.

5. Sun Y, Jin C, Zhan F, Wang X, Liang M, Zhang Q, Ding S, Guan X, Huo X, Li C, et al. Host cytokine storm is associated with disease severity of severe fever with thrombocytopenia syndrome. J Infect Dis. 2012;206(7):1085-94.

6. Deng B, Zhang S, Geng Y, Zhang Y, Wang Y, Yao W, Wen Y, Cui W, Zhou Y, Gu Q, et al. Cytokine and chemokine levels in patients with severe fever with thrombocytopenia syndrome virus. PLoS One. 2012;7(7):e41365.

7. Li J, Han Y, Xing Y, Li S, Kong L, Zhang Y, Zhang L, Liu N, Wang Q, Wang S, et al. Concurrent measurement of dynamic changes in viral load, serum enzymes, T cell subsets, and cytokines in patients with severe fever with thrombocytopenia syndrome. PLoS One. 2014;9(3):e91679.

8. Ning YJ, Feng K, Min YQ, Cao WC, Wang M, Deng F, Hu Z, Wang H. Disruption of type I interferon signaling by the nonstructural protein of severe fever with thrombocytopenia syndrome virus via the hijacking of STAT2 and STAT1 into inclusion bodies. J Virol. 2015;89(8):4227-36.

9. Santiago FW, Covaleda LM, Sanchez-Aparicio MT, Silvas JA, Diaz-Vizarreta AC, Patel JR, Popov V, YU XJ, Garcia-Sastre A, Aguilar PV. Hijacking of RIG-I signaling proteins into virus-induced cytoplasmic structures correlates with the inhibition of type I interferon responses. J Virol. 2014;88(8):4572-85.

10. Liu Y, Wu B, Paessler S, Walker DH, Tesh RB, Yu XJ. The pathogenesis of severe fever with thrombocytopenia syndrome virus infection in alpha/beta interferon knockout mice: insights into the pathologic mechanisms of a new viral hemorrhagic fever. J Virol. 2014;88(3):1781-6.

11. Yang ZD, Hu JG, Lu QB, Guo CT, Cui N, Peng W, Wang LY, Qin SL, Wang HY, Zhang PH, et al. The prospective evaluation of viral loads in patients with severe fever with thrombocytopenia syndrome. J Clin Virol. 2016;78:123-8.

12. Lackie J: A dictionary of biomedicine. In.: Oxford University Press; 2010. ISBN 9780191044953

13. Dinarello CA. Proinflammatory cytokines. Chest. 2000;118(2):503-8.

14. Parkin J, Cohen B. An overview of the immune system. Lancet. 2001;357(9270):1777-89.

15. Dipaola M, Smith T, Ferencz-Biro K, Liao MJ, Testa D. Interferon-alpha 2 produced by normal human leukocytes is predominantly interferon-alpha 2b. J Interf Res. 1994;14(6):325-32.

16. Pestka S, Krause CD, Walter MR. Interferons, interferon-like cytokines, and their receptors. Immunol Rev. 2004;202:8-32.

17. Schultz $U$, Kaspers B, Staeheli P. The interferon system of non-mammalian vertebrates. Dev Comp Immunol. 2004;28(5):499-508.

18. Samarajiwa SA, Wilson W, Hertzog PJ. The interferons: characterization and application. Weinheim: WILEY-VCH Verlag GmbH \& Co; 2006.

19. McNab F, Mayer-Barber $K$, Sher A, Wack A, O'Garra A. Type I interferons in infectious disease. Nat Rev Immunol. 2015;15(2):87-103.

20. Cameron MJ, Ran L, Xu L, Danesh A, Bermejo-Martin JF, Cameron CM, Muller MP, Gold WL, Richardson SE, Poutanen SM, et al. Interferon-mediated immunopathological events are associated with atypical innate and adaptive immune responses in patients with severe acute respiratory syndrome. J Virol. 2007:81(16):8692-706.

21. Morzunov SP, Khaiboullina SF, St Jeor S, Rizvanov AA, Lombardi VC. Multiplex Analysis of Serum Cytokines in Humans with Hantavirus Pulmonary Syndrome. Front Immunol. 2015;6:432.

22. Prescott J, Ye C, Sen G, Hjelle B. Induction of innate immune response genes by Sin Nombre hantavirus does not require viral replication. J Virol. 2005;79(24):15007-15.

23. Ning YJ, Wang M, Deng M, Shen S, Liu W, Cao WC, Deng F, Wang YY, Hu Z, Wang $\mathrm{H}$. Viral suppression of innate immunity via spatial isolation of TBK1/IKKepsilon from mitochondrial antiviral platform. J Mol Cell Biol. 2014;6(4):324-37. 
24. Gai ZT, Zhang Y, Liang MF, Jin C, Zhang S, Zhu CB, Li C, Li XY, Zhang QF, Bian PF, et al. Clinical progress and risk factors for death in severe fever with thrombocytopenia syndrome patients. J Infect Dis. 2012;206(7):1095-102.

25. Metcalf $D$. The granulocyte-macrophage colony-stimulating factors. Science. 1985;229(4708):16-22.

26. Chen H, Hu K, Zou J, Xiao J. A cluster of cases of human-to-human transmission caused by severe fever with thrombocytopenia syndrome bunyavirus. Int J Infect Dis. 2013;17(3):e206-8.

27. Weng Y, Chen N, Han Y, Xing Y, Li J. Clinical and laboratory characteristics of severe fever with thrombocytopenia syndrome in Chinese patients. Braz J Infect Dis. 2014;18(1):88-91.

28. Cui N, Bao XL, Yang ZD, Lu QB, Hu CY, Wang LY, Wang BJ, Wang HY, Liu K, Yuan $\mathrm{C}$, et al. Clinical progression and predictors of death in patients with severe fever with thrombocytopenia syndrome in China. J Clin Virol. 2014:59(1):12-7.

29. Brocker C, Thompson D, Matsumoto A, Nebert DW, Vasiliou V. Evolutionary divergence and functions of the human interleukin (IL) gene family. Hum Genomics. 2010;5(1):30-55

30. Hirano T, Yasukawa K, Harada H, Taga T, Watanabe Y, Matsuda T, Kashiwamura S, Nakajima K, Koyama K, Iwamatsu A, et al. Complementary DNA for a novel human interleukin (BSF-2) that induces B lymphocytes to produce immunoglobulin. Nature. 1986;324(6092):73-6.

31. Rousset F, Garcia E, Defrance T, Peronne C, Vezzio N, Hsu DH, Kastelein R, Moore KW, Banchereau J. Interleukin 10 is a potent growth and differentiation factor for activated human B lymphocytes. Proc Natl Acad Sci U S A. 1992;89(5):1890-3.

32. Ng LF, Chow A, Sun YJ, Kwek DJ, Lim PL, Dimatatac F, Ng LC, Ooi EE, Choo KH, Her Z, et al. IL-1beta, IL-6, and RANTES as biomarkers of Chikungunya severity. PLoS One. 2009;4(1):e4261

33. McElroy AK, Erickson BR, Flietstra TD, Rollin PE, Nichol ST, Towner JS, Spiropoulou CF. Biomarker correlates of survival in pediatric patients with Ebola virus disease. Emerg Infect Dis. 2014;20(10):1683-90.

34. Lalani I, Bhol K, Ahmed AR. Interleukin-10: biology, role in inflammation and autoimmunity. Ann Allergy Asthma Immunol. 1997;79(6):469-83.

35. Kriegler M, Perez C, DeFay K, Albert I, Lu SD. A novel form of TNF/cachectin is a cell surface cytotoxic transmembrane protein: ramifications for the complex physiology of TNF. Cell. 1988;53(1):45-53.

36. Le $Y$, Zhou Y, Iribarren $P$, Wang J. Chemokines and chemokine receptors: their manifold roles in homeostasis and disease. Cell Mol Immunol. 2004;1(2):95-104.

37. Melik-Parsadaniantz S, Rostene W. Chemokines and neuromodulation. J Neuroimmunol. 2008;198(1-2):62-8.

38. Levy JA. The unexpected pleiotropic activities of RANTES. J Immunol. 2009:182(7):3945-6.

39. Makino Y, Cook DN, Smithies O, Hwang OY, Neilson EG, Turka LA, Sato H, Wells AD, Danoff TM. Impaired T cell function in RANTES-deficient mice. Clin Immunol. 2002;102(3):302-9.

40. Osterholm MT. Preparing for the next pandemic. N Engl J Med. 2005;352(18):1839-42.

41. Wang $\mathrm{H}, \mathrm{Ma} \mathrm{S}$. The cytokine storm and factors determining the sequence and severity of organ dysfunction in multiple organ dysfunction syndrome. Am J Emerg Med. 2008;26(6):711-5.

42. Rothman AL. Immunity to dengue virus: a tale of original antigenic sin and tropical cytokine storms. Nat Rev Immunol. 2011;11(8):532-43.

43. Guabiraba R, Marques RE, Besnard AG, Fagundes $C T$, Souza DG, Ryffel B, Teixeira MM. Role of the chemokine receptors CCR1, CCR2 and CCR4 in the pathogenesis of experimental dengue infection in mice. PLoS One. 2010;5(12):e15680.

44. Oh WS, Heo ST, Kim SH, Choi WJ, Han MG, Kim JY. Plasma exchange and ribavirin for rapidly progressive severe fever with thrombocytopenia syndrome. Int J Infect Dis. 2014;18:84-6.

\section{Submit your next manuscript to BioMed Central and we will help you at every step:}

- We accept pre-submission inquiries

- Our selector tool helps you to find the most relevant journal

- We provide round the clock customer support

- Convenient online submission

- Thorough peer review

- Inclusion in PubMed and all major indexing services

- Maximum visibility for your research

Submit your manuscript at www.biomedcentral.com/submit
) Biomed Central 